\title{
NOVAS OCORRÊNCIAS DE URÂNIO NA REGIÃO DE LAGOA REAL, A PARTIR DA SUPERPOSIÇÃO DE DADOS GEOFÍSICOS, GEOLÓGICOS E DE SENSORIAMENTO REMOTO
}

\author{
ELISABETE MARIA PASCHOLATI ${ }^{1}$, CLAUZIONOR LIMA DA SILVA ${ }^{2}$, \\ SOLANGE DOS SANTOS COSTA ${ }^{3}$, LILIANA SAYURI OSAKO ${ }^{4}$, \\ GILBERTO AMARAL (In memorian) ${ }^{1} \&$ INGRID PADILLA RODRIGUEZ ${ }^{5}$
}

\begin{abstract}
NEW OCCURRENCES OF URANIUM IN THE LAGOA REAL REGION USING A GEOPHYSICAL, GEOLOGICAL AND REMOTE SENSING SUPPERPOSITION The origin and control of Uranium occurrences and deposits at the Uraniferous District of Lagoa Real, State of Bahia (Brazil), has been largely studied over the last decades. Currently, the deposit controls are bounded to albitites in the Granite-Gneissic Complex at the center-south area of Lagoa Real. Data from the São Timóteo Airborne Geophysical Project have been analyzed and superimposed to geological, geophysical and remote sensing data in order to identify new occurrences of Uranium for prospection. Reappraisal of the gammaspectrometric data (K, $\mathrm{U}$ e Th) shows that distinctive litotypes indicate some radiometric anomalies in the northeast area. The magnetometric data suggest the existence of depth-rooted magnetic blocks separated by shear zones recognized by the Landsat-5TM's image. The combination of these products with the geological information shows a structural evolution not previously described in literature. The kinematics of the shear zones with $\mathrm{N}-$ S, NE-SW and NE-SW directions was established based on bodies' displacement and magnetic features. The ductile-ruptile, ruptileductile and ruptile structures are compatible with the geological framework of the São Francisco Craton during the Brazilian Cicle: East-West convergence with West mass transport. The continuing deformation produced dextral and sinistral shear zones that resulted in the inflection of the pre-existent foliation. The well-known Uranium deposits are located in the N-S shear zones; the new occurrences, located in the northeastern area, are associated with the NW-SE shear zones and they introduce new targets for prospection.
\end{abstract}

Keywords: airborne geophysics, geology, remote sensing, São Timóteo Project

\begin{abstract}
Resumo O Distrito Uranífero de Lagoa Real, no estado da Bahia, tem sido alvo de diversos estudos sobre a origem e o controle das ocorrências de Urânio, no decorrer das últimas décadas. Atualmente, o controle dos depósitos restringe-se aos albititos do Complexo Granito-Gnáissico localizados na porção centro-sul em Lagoa Real. Os dados do Projeto Aerogeofísico São Timóteo foram analisados e superpostos aos dados geológicos e de sensoriamento remoto, com o objetivo de identificar novas ocorrências promissoras à prospecção de Urânio. Com a reavaliação de dados gamaespectrométricos $(\mathrm{K}, \mathrm{U}, \mathrm{Th})$, distintos litotipos evidenciam áreas com anomalias radiométricas no setor nordeste. Os dados magnetométricos mostram blocos magnéticos distintos, de natureza profunda, que estão compartimentados por zonas de cisalhamento reconhecidas em imagens Landsat-5/TM. A integração desses produtos com as informações geológicas disponíveis evidenciam um quadro geológico-estrutural até então não descrito na literatura. A cinemática de zonas de cisalhamento com direções N-S, NE-SW e NW-SE foi estabelecida a partir de deslocamentos de corpos e feições magnéticas. As estruturas dúctil-rúptil, rúptil-dúctil e rúptil observadas também são compatíveis com um quadro geológico regional no Cráton São Francisco durante o Brasiliano: convergência leste-oeste com transporte de massa para oeste. A progressão da deformação produziu zonas de cizalhamento dextral e sinistral, que resultaram na inflexão da foliação pré-existente. As jazidas de Urânio conhecidas estão associadas a zonas de cisalhamento N-S e as novas ocorrências, na parte nordeste da área, estão associadas a zonas de cisalhamento NW-SE e representam novos alvos para prospecção.
\end{abstract}

Palavras-chaves: aerogeofísica, geologia, sensoriamento remoto, Projeto São Timóteo

INTRODUĊ̃̃O O Distrito Uranífero de Lagoa Real, no Estado da Bahia, foi descoberto após inúmeros levantamentos aerogeofísicos sistemáticos decorrentes de estudos sobre Urânio no Quadrilátero Ferrífero. Os primeiros levantamentos realizados em escala regional foram os projetos Espinhaço Setentrional (1975)e Diamantina (1976), seguidos do Projeto Urandi (1976/1977), em maior escala. As fortes anomalias uraníferas determinadas na região de Lagoa Real possibilitaram, em 1979, a execução do levantamento gamaespectrométrico e magnético São Timóteo, o qual confirmou a existência de uma série de ocorrências de Urânio (Oli-

\footnotetext{
1 - UNICAMP/IG/DGRM, Caixa Postal 6152 , Campinas, SP, e-mail: paschol@ige.unicamp.br

2 - UNESP/IGCE - UFAM/ DEGEO, Caixa Postal 178, Rio Claro, SP, e-mail: clauzionor silva@hotmail.com

3 - UNICAMP/IG - UFAM/ DEGEO, Caixa Postal 6152, Campinas, SP, e-mail: solange@ige.unicamp.br

4 - UFPE/CTG/DEGEO, Caixa Postal 7852, Recife, PE, e-mail: lilianaso@zipmail.com

5 - UNICAMP/IG/DGRM - IGP/DG (Cuba), Caixa Postal 6152, Campinas, SP, e-mail: Ingrid@ige.unicamp.br
} 
veira et al. 1985, CPRM 1995).

Desde então, vários estudos geológicos e geofísicos se sucederam na investigação sobre a origem e o controle dessas ocorrências (Fuzikawa 1982, Villaça \& Hashizume 1982, Ribeiro et al. 1984, Brito et al. 1984, Raposo et al. 1984, Alves e Fuzikawa 1984, Oliveira et al. 1985, Maruéjol et al. 1987, Lobato e Fyfe 1990). Estes autores, dentre outros, sugerem que os depósitos de Urânio de Lagoa Real estão associados à tríade mineralização, cisalhamento e metassomatismo, cujo controle geológico-estrutural distinto é particular no mundo. Osako (1999), com enfoque nas ocorrências em albititos mineralizados, mostrou que a interpretação de dados aerogeofísicos e de sensoriamento remoto, na porção centro-sul do Projeto São Timóteo, permitem a caracterização geológico-estrutural dessas ocorrências e de possíveis áreas anômalas de depósito de Urânio.

Com o propósito de identificar áreas anômalas, os dados do Projeto São Timóteo foram reavaliados, com enfoque especial à região nordeste da área (Fig. 1). Os dados magnéticos e gamaespectrométricos foram re-processados e integrados aos produtos de sensores remotos Landsat-5TM e às informações geológicas e estruturais disponíveis na literatura. Essa análise possibilitou mapear as ocorrências dos corpos albitíticos mineralizados, já descritos anteriormente, e de possíveis áreas promissoras com altas concentrações de Urânio na porção nordeste da região. Feições estruturais importantes são apresentadas e mostram estreita relação entre a ocorrência desses depósitos e o quadro geológico-estrutural do Pré-Cambriano.

SÍNTESE GEOLÓGICA REGIONAL A região de Lagoa Real está situada na porção centro-sul do Cráton São Francisco (Fig. 2). O embasamento dessa região é representado por rochas do Arqueano/Paleoproterozóico e corresponde a granulitos, migmatitos e gnaisses dos blocos Paramirim e Gavião (Inda \& Barbosa 1996). A unidade vulcanossedimentar Ibitira-Brumado corresponde a rochas supracrustais, anfibolitos, formação ferrífera bandada, gnaisses, metacherts, mármores e xistos, inclusive cinturões granito-greenstones (Turpin et al. 1988, Lobato \& Fyfe 1990, Cordani et al. 1992). O Complexo Granítico-Gnáissico Lagoa Real, do Paleoproterozóico, estende-se na direção norte-sul e abrange uma área superior a $2.000 \mathrm{~km}^{2}$. Essa unidade, do domínio do bloco Paramirim, compreende corpos graníticos alcalinos a subalcalinos, ortognaisses alongados, albititos e leucodioritos pouco deformados. As mineralizações de Urânio estão associadas aos albititos alongados e às zonas de cisalhamento, cuja gênese deve-se a interação entre fluidos alcalinos e rochas encaixantes. O Supergrupo Espinhaço, do Mesoproterozóico, é constituído por arenitos, conglomerados, siltitos, folhelhos, quartzitos, xistos e pela seqüência de vulcânicas ácidas, riolitos e riodacitos. Coberturas detrítico-laterítica terciárias e sedimentos aluviais quaternários completam o quadro geológico dessa região.

O contexto geológico e tectônico da região de Lagoa Real faz parte da evolução do Cráton São Franscisco e dos ciclos ou eventos geológicos sucessivos: Jequié, Transamazônico, Espinhaço e Brasiliano (Almeida 1977, Cordani \& Brito Neves 1982, Fyfe 1979). A mineralização de Urânio está relacionada às deformações oriunda da colisão N-S, com transporte tectônico de leste para oeste, durante o evento Brasiliano. Este envolveu a deformação de rochas do Arqueano, Paleoproterozóico e Mesoproterozóico, no qual as rochas mais antigas (embasamento arqueano gnáissico) foram sobrepostas aos metassedimentos do Supergrupo Espinhaço (Caby \& Arthaud 1987). Mecanismos de retrometamorfismo e al-

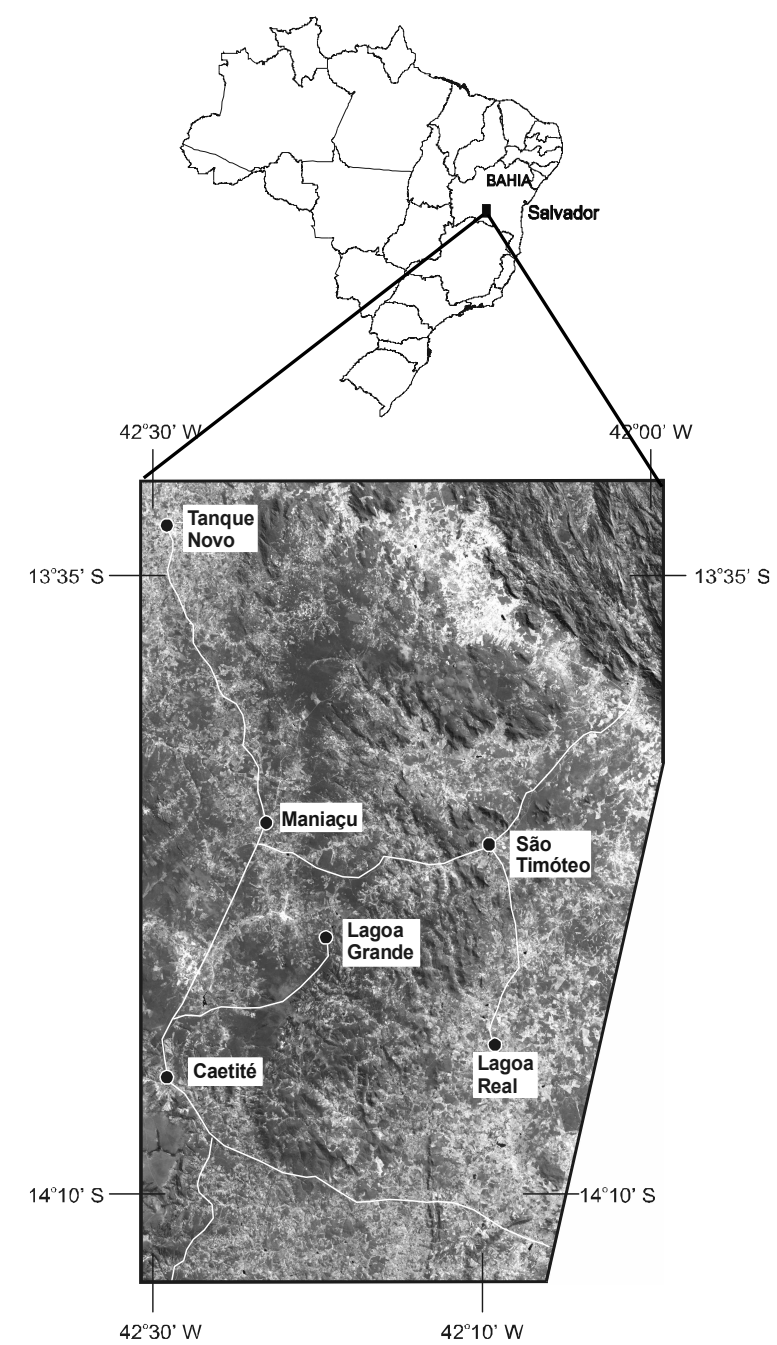

Figura 1 - Localização da área do Levantamento Aerogeofísico Projeto São Timóteo, Bahia, (gamaespectrometria e magnetometria), na imagem Landsat-5TM

teração metassomática ao longo das zonas de cisalhamento N-S, possibilitou a formação de corpos de albititos alongados mineralizados (Lobato et al. 1983a,b, Lobato \& Fyfe 1990).

GEOFÍSICA Foram utilizados os dados aerogeofísicos do Projeto São Timóteo, executado pela Geofoto, contratada pela NUCLEBRÁS em convênio com a CPRM, em 1979. As linhas de vôo possuem direção leste-oeste com espaçamento de $500 \mathrm{~m}$ e altura nominal de vôo de $150 \mathrm{~m}$. O levantamento constou de medidas gamaespectrométricas de Contagem Total (CT) e dos canais do Potássio (K), Urânio (U) e Tório (Th), em cps (contagem por segundo) e magnetométricas de Campo Total (CMT), em nT (nanotesla). A compilação geológica foi realizada a partir do Mapa Geológico do Brasil, 1:2.500.000 (Bizzi et al. 2001) e do Projeto Lagoa Real, 1:25.000 (Costa et al. 1985).

Processamento gama Os dados obtidos foram pré-processados para a correção de altura, efeito Compton e background. $\mathrm{O}$ processamento realizado envolveu a análise estatística para verificação da consistência dos dados, conversão dos valores quali- 

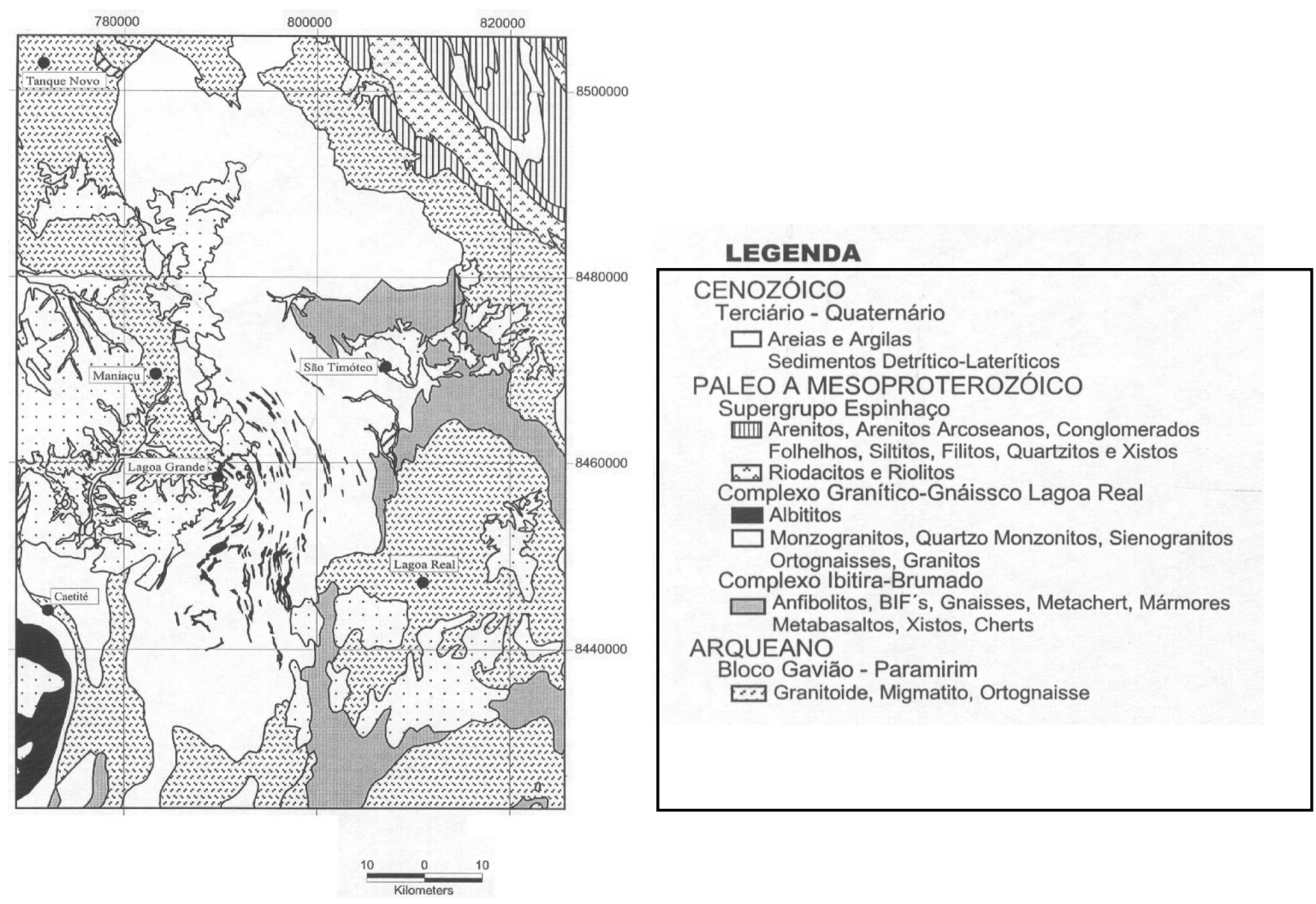

Figura 2 - Mapa geológico da região do Projeto São Timóteo, Bahia (modificado de Bizzi et al. 2001, escala 1:2.500.000 e Costa et al. 1985, escala 1:25.000).

tativos de K, U e Th, para "semiquantitativos" (de cps para percentagem e ppm), de acordo com Amaral \& Pascholati (1998), interpolação por curvatura mínima (célula de $125 \mathrm{~m}$ ), segundo Briggs (1974), e micro-nivelamento para eliminação de distorções das linhas de vôo (Minty 1991). As áreas anômalas foram identificadas de acordo com Solovov (1987).

Imagem ternária de composição colorida no domínio RBG foi elaborada a fim de correlacionar a distribuição dos radioelementos com as unidades geofísicas (Duval 1985, Milligan \& Gunn 1997), calcular as razões Th/K e do parâmetro F (eU x K/eTh) (Gnojek \& Prichystal 1985), identificar o grau de alteração hidrotermal (Grasty 1975) e determinar a razão Th/U para verificação do grau de diferenciação dentro de suítes ígneas (Dickson \& Scott 1997). A análise por principais componentes (Drury 1987) também foi efetuada com o objetivo de se verificar o grau de correlação entre os vários radioelementos.

Processamento magnético No pré-processamento os dados magnéticos foram corrigidos para a variação diurna e reduzidos do IGRF. No processamento, verificou-se a consistência dos dados, efetuou-se a interpolação por curvatura mínima (125 m), micronivelamento de acordo com Minty (1991), análise do espectro da potência e filtragens (redução ao equador, continuação ascendente, derivadas direcionais e sinal analítico-amplitude e fase) (Nettetlon \& Cannon 1962, Clark 1997, Gunn \& Dentith 1997).

SENSORIAMENTOREMOTO A imagemutilizada foia Landsat5TM, 218/69, de 1987, constituída pelas bandas, 1, 2, 3, 4, 5 e 7. No pré-processamento foram efetuadas a correção geométrica e aná- lise estatística de cada banda. No processamento, foram geradas composições coloridas, em RGB, análises espectrais para cada banda e principais componentes.

RESULTADOS E DISCUSSÕES Os resultados obtidos pela gamaespectrometria, magnetometria e sensoriamento remoto foram integrados de forma a compará-los com a geologia da área, tanto do ponto de vista litoestrutural, como para identificar possíveis áreas alvo para a prospecção de Urânio.

A figura 3 mostra a imagem ternária gamaespectrométrica $\mathrm{K}$, eU e eTh, superposta aos depósitos e ocorrências de Urânio conhecidas e ao mapa geológico. As áreas em branco representam a maior concentração dos três radioelementos (eTh, eU e K) e em preto, a menor concentração. As médias obtidas foram 1,65\% para o Potássio, 7,7 ppm para o Urânio e 18,2 ppm para o Tório. Observa-se que depósitos e ocorrências da porção central de Lagoa Real coincidem com a cor amarelo-limão, resultante da razão eU/K. O mesmo resultado é encontrado na porção nordeste da área.

O Complexo Granítico-Gnaíssico Lagoa Real, na porção central responde pela variação do amarelo ao vermelho com altos teores de $\mathrm{K}$ e eU e, subordinadamente, em magenta, com altos teores de K e eTh. Nas porções norte, nordeste (direção NW-SE) e central da imagem pode-se visualizar setores em ciano que também correspondem a altos teores de eTh e eU.

A cobertura cenozóica detrítico-laterítica, a oeste, é identificada pelo azul. A extensão desses depósitos pode ser mapeada pelo alto teor de Tório, tendo em vista que esse elemento possui baixa solubilidade e pode se associar a óxidos de ferro, como em crostas lateríticas (Dickson \& Scott 1997). O bloco Paramirim do Arqueano, 
Novas ocorrências de Urânio na região de Lagoa Real, a partir da superposição de daados geofísicos, geológicos e de sensoriamento remoto
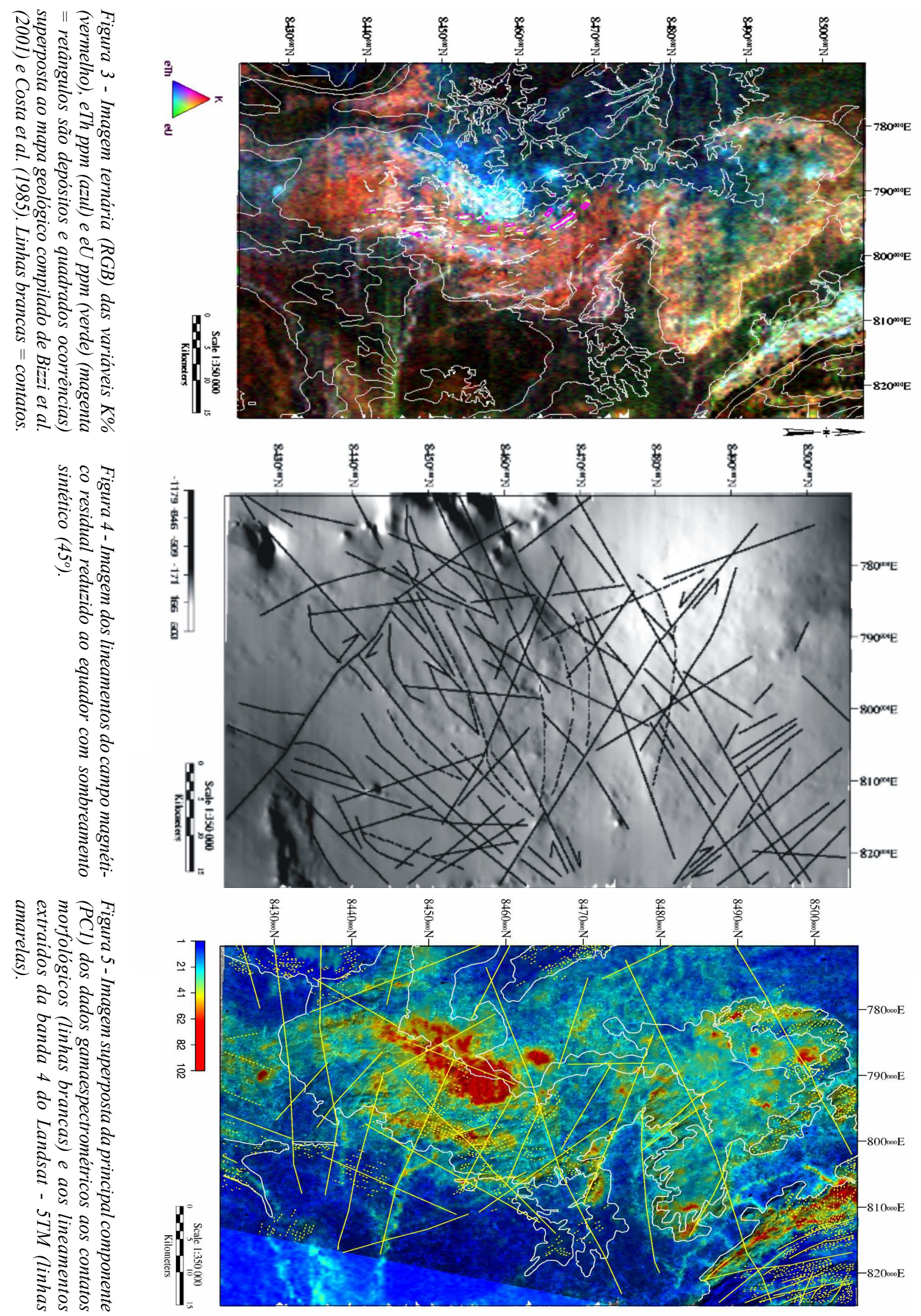
que circunda o Complexo-Gnáissico Lagoa Real, resulta em tons verde-amarronzados e a menor freqüência de $\mathrm{K}$, eTh e eU, a leste da área, também representa os litotipos arqueanos ainda não mapeados.

Tanto as ocorrências e os depósitos de e U mapeados na área central, como áreas de prováveis ocorrências a nordeste, são evidentes na integração da imagem do eU com a primeira derivada vertical do campo magnético anômalo reduzido ao equador. As mineralizações conhecidas coincidem, na parte central, com estruturas magnéticas, os lineamentos e a foliação e, na porção nordeste, às descontinuidades magnéticas NW-SE.

A análise do parâmetro $F$ realçou o alto grau de alteração hidrotermal (variação de 2 a 12) e a razão $\mathrm{K} / \mathrm{Th}$ mostrou resposta semelhante (valor 12), corroborando com as informações obtidas no paarágrafo anterior, principalmente na porção nordeste onde as ocorrências de Urânio não eram reconhecidas.

As unidades geológicas podem ser reconhecidas pela textura na imagem de primeira derivada do campo magnético reduzido ao equador, com sombreamento sintético $\left(45^{\circ}\right)$ (Fig. 4). As unidades do embasamento e do Supergrupo Espinhaço, ambos com textura lisa, envolvem o Complexo Granítico-Gnáissico Lagoa Real, de textura rugosa. Essa figura permite ainda a identificação de lineamentos magnéticos coincidentes com as feições estruturais conhecidas como as foliações e zonas de cisalhamento com direção NNE-SSW, NW-SE, NE-SW e NW-SE.

A imagem do campo magnético anômalo, quando associada à imagem de continuação ascendente, evidencia três domínios magnéticos distintos. Uma evidente descontinuidade separa um corpo de raiz profunda, com valores elevados e direção E-W, a norte, de um setor de valores intermediários, com orientação aproximada NE-SW, ao centro. A sudeste se encontra o domínio que apresenta os menores valores e pode ser associado ao bloco GaviãoParamirim. As várias descontinuidades observadas mostram feições geométricas bem definidas, inclusive na região NW-SE.

A principal componente ( $\mathrm{PC} 1)$ dos dados gamaespectrométricos e os dados magnéticos foram superpostos aos contatos morfológicos e aos lineamentos extraídos da banda 4 da imagem Landsat-5TM.

A análise da imagem Landsat-5TM permitiu individualizar cinco unidades morfoestruturais (Fig. 5). A unidade à nordeste compreende as rochas alongadas e deformadas do Supergrupo Espinhaço com arranjo estrutural NW-SE, similar ao da porção sudoeste. Na região central, as feições N-S correspondem ao Complexo GraníticoGnáissico Lagoa Real. Os elementos morfoestruturais desse complexo são lineamentos N-S, NE-SW, NW-SE e WNW-ESE, e correspondem as foliações, fraturas, falhas e zonas de cisalhamento, onde a inflexão é bem marcada.

As regiões a oeste e a leste, marcadas por uma superfície arrasada e com escassez de foliação, correspondem ao embasamento arqueano. Nessas áreas podem ser reconhecidos importantes lineamentos superficiais na imagem Landsat-5TM que constituem estruturas NE-SW com padrão similar as estruturas magnéticas das rochas daquele setor.

A oeste, próximo ao contato com o Complexo Granítico-Gnáissico Lagoa Real, a estreita faixa alongada N-S que se amplia mais ao norte, corresponde à cobertura cenozóica detrítico-laterítica. As crostas ferruginosas e/ou os silcretes discriminados na imagem gamaespectrométrica podem ser mapeados pelos tons verde e azul (Fig. 5). De acordo com Dickson \& Scott (1997) e Wilford et al. (1997) essa variação indica ausência de Potássio e presença de Tório e Urânio, visto que o alto valor de Tório é retido em óxidos de Ferro, como na região de Lagoa Real (Osako et al. 1997). No entanto, crostas ferruginosas desenvolvidas em formações de greenstone podem aparecer em tons escuros e refletir a ausência desses radioelementos, justamente na rocha onde os óxidos de Ferro são originados. Pelo fato dessa unidade apresentar essa característica, é possível que essa cobertura cenozóica represente um sistema deposicional moderno, cuja evolução geológica deve ser alvo de investigação sistemática. A extensão de coberturas detrito-lateríticas deve, portanto, ser maior que a apresentada nos mapas por Costa et al. (1985) e Bizzi et al. (2001), pois a alta concentração de Tório (observada na Fig. 3) é compatível com a unidade morfoestrutural estabelecida. Desse modo, é possível que essa cobertura cenozóica represente um sistema deposicional moderno a ser investigado.

A derradeira unidade morfológica a ser discutida compreende uma pequena área situada a sul do Complexo Granítico-Gnáissico Lagoa Real e corresponde a rochas arqueanas do Complexo IbitiraBrumado. Estende-se ao longo de um trend N-S marcado por expressivos lineamentos e foliação geral compatível com esse arranjo. Pode-se notar ainda, que os compartimentos morfológicos ou morfoestruturais estão marcados, em grande parte, por importantes descontinuidades que os limitam ou cortam. Cruz \& Alckmin (2002) reportam que os contatos oeste e leste do Complexo Granítico-Gnáissico Lagoa Real são marcados por zonas de cisalhamento dúcteis e rúpteis a dúcteis de caráter reverso.

Os lineamentos extraídos da imagem Landsat-5TM e da imagem de campo magnético anômalo, aliados às principais unidades morfológicas, permitiram reconhecer um arranjo de estruturas dúctil-rúptil, rúptil-dúctil e rúptil (falhas). Essas estruturas são notadas pelo arranjo de foliações, feições sigmoidais e falhas presentes nas unidades arqueana e paleoproterozóica e mesoproterozóica (unidades do bloco Gavião-Paramirim, Complexo Ibitira-Brumado, Complexo Granítico-Gnáissico Lagoa Real e Supergrupo Espinhaço). As feições em sigmóides no Complexo Lagoa Real mostram inflexões na foliação pretérita quando da atuação de zonas de cisalhamento transversais a elas.

A inflexão da foliação da unidade Lagoa Real já havia sido mencionada nos trabalhos de Ribeiro et al. (1984), Costa et al. (1985) e Caby \& Arthaud (1987). A forma em arco dos albititos e a variação da foliação com mergulhos para oeste, na porção sul, subvertical, na parte central, e para leste na extremidade norte, seria compatível com uma torção do tipo helicoidal (Oliveira et al. 1985). No entanto, a primeira referência sobre a atuação de zonas de cisalhamento rúpteis, dextral e sinistral, como responsáveis da deformação da foliação pretérita, deve-se a Caby \& Arthaud (1987).

Alguns indicadores cinemáticos, como deslocamentos ou contato abrupto de corpos magnéticos, estiramento de isolinhas do campo magnético e feições sigmoidais, foram reconhecidos no mapa do campo magnético anômalo. Esse tipo de análise cinemática de lineamentos tem sido utilizado por Gunn (1997a, b) e Costa et al. (2002). Como suporte a essas interpretações estruturais, foi elaborado o mapa de linhas de forma a partir do mapa de foliação do Complexo Granítico-Gnáissico Lagoa Real de Costa et al. (1985) e Osako (1999) (Fig. 6). Apesar deste produto ser apenas de parte da área de estudo é possível notar zonas de cisalhamento dextrais, com direção ENE-WSW, e sinistrais N-S, e também a inflexão da foliação de N-S para NW, na parte norte. Esses dois domínios da foliação a norte e a sul são individualizados por meio de zonas de cisalhamento ENE-WSW. As feições sigmoidais são produtos de zonas de cisalhamentos e as formas encurvadas da foliação indicam a cinemática das estruturas. Quanto à mudança de atitude 
pode-se notar que os altos ângulos de mergulhos e o caráter reverso estão associados à interação com as zonas de cisalhamento.

As unidades geológicas, os lineamentos estruturais e as ocorrências de Urânio foram integradas à imagem ternária (RGB$\mathrm{KeUeTh}$ ) na figura 7. As anomalias consideradas a partir de 23,4 ppm coincidem com as jazidas de Urânio do Distrito de Lagoa Real em granitos e gnaisses pouco deformados a oeste dos albititos, conforme mostrado por Osako (1999). Na região a nordeste, no contato das unidades do Supergrupo Espinhaço com o embasamento arqueano, ocorrem várias concentrações anômalas de Urânio ao longo das descontinuidades com direção NW-SE. Ao lado, separadas por uma faixa do embasamento, já no domínio do Complexo Granítico-Gnáissico Lagoa Real, outras anomalias também estão relacionadas às zonas de cisalhamento sinistral NW$\mathrm{SE}$, como a do setor noroeste.

A ocorrência da mineralização de Urânio em Lagoa Real tem sido associada às zonas de cisalhamento N-S dúctil e envolve ainda a combinação de fatores metassomático e de retrometamorfismo (Lobato et al. 1983b, Brito et al. 1984, Oliveira et al. 1985, Maruéjol et al. 1987, Caby \& Arthaud 1987, Lobato \& Fyfe 1990, Osako 1999, Osako \& Amaral 2000). A origem de Urânio é proveniente das rochas do Supergrupo Espinhaço, conforme proposto por Lobato et al. (1983a) e Lobato \& Fyfe (1990). As novas anomalias do setor nordeste estão localizadas no contato do embasamento com o Supergrupo Espinhaço, associadas a zonas de cisalhamento NW-SE e, portanto, podem representar áreas promissoras para a investigação.

O resultado da análise estrutural compreende os sistemas de zona de cisalhamento reversas de direção N-S e NW-SE, dextrais NW-SE, E-W e NE-SW e sinistrais N-S e NW-SE (Figs. 8 e 9). O modelo tectônico da região do Distrito Uranífero de Lagoa Real sugere uma deformação progressiva a partir do sistema de colisão inicial de leste para oeste, com transporte para oeste. Com a progressão da deformação, formaram-se rampas laterais sincrônicas aos empurrões (fase colisional 1). Para acomodar a deformação resultante da colisão de dois blocos com natureza distinta, zonas de fuga de massas evoluíram em e desenvolveram zonas de cisalhamento sinistrais e dextrais com foliação pretérita produzida pelos empurrões (fase colisional 2). A falha dextral NW-SE da porção sul, evidenciada pelo deslocamento de corpos magnéticos, é uma exceção ao processo e provavelmente é de reativação. A interação de zonas de cisalhamento com a foliação pré-existente na parte sul da região do Distrito Uranífero de Lagoa Real, promove a mudança de atitude da foliação. Na área norte a atuação dessa deformação resulta na rotação do bloco norte da área. Componentes de movimentação normal-oblíqua podem também fazer parte desse sistema como decorrentes da interação entre blocos.

CONCLUSÕES O re-processamento dos dados aerogeofísicos do Projeto São Timóteo e de sensoriamento remoto da imagem Landsat-5TM, aliados às informações geológicas permitiram inferir feições estruturais associadas a anomalias de Urânio na região nordeste da área. As feições estruturais dúctil-rúptil, rúptil-dúctil

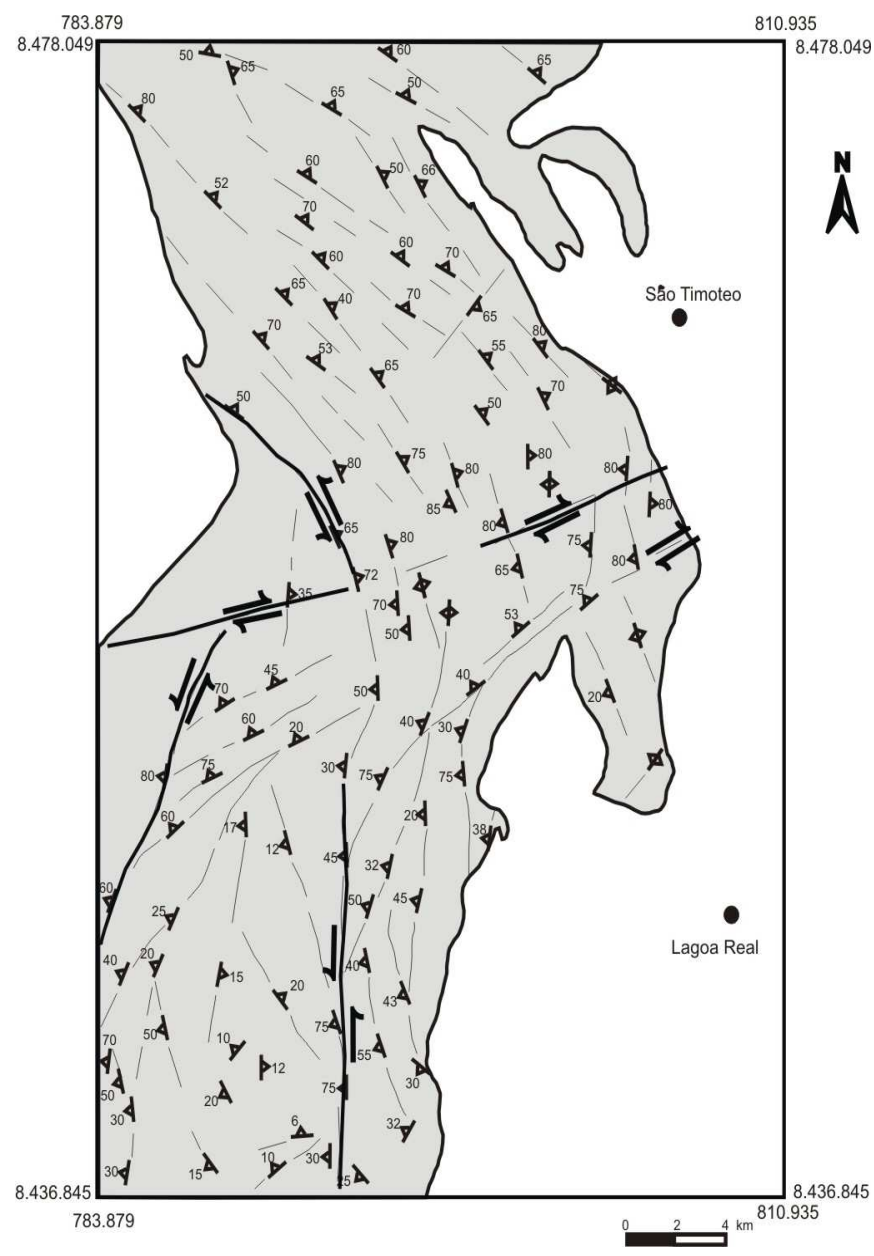

Figura 6 - Mapa de linhas de forma extraído do mapa de foliação de Costa et al. (1985) e Osako (1999).

e rúptil observadas são compatíveis com o quadro de deformação progressiva associada ao encurtamento oriundo da convergência leste-oeste, com transporte para oeste no Cráton São Francisco. Porém, com a continuidade da deformação, a fase de empurrão frontal é acomodada por meio de fuga lateral de massa, originando zonas de cisalhamentos transcorrentes dextral e sinistral, que causam a inflexão da foliação pré-existente. As jazidas conhecidas de Urânio localizadas em zonas de cisalhamento N-S, correspondem a zonas de distensão entre duas zonas de cisalhamento. As novas ocorrências na parte nordeste da área, também correspondem a zonas de cisalhamentos de acordo com o quadro geológico-estrutural proposto.

Agradecimentos À Nuclebrás, pela cessão dos dados aerogeofísicos, aos colegas Carlos Tapia e Mario Araújo pelas discussões e aos revisores da RBG pelas sugestões ao manuscrito.

\section{Referências}

Almeida F.F. 1977. O Cráton do São Francisco. Rev. Bras.Geoc., 7:349364.

Alves J.V., Fuzikawa K. 1984. O estudo de inclusões fluidas da jazida uranífera de Cachoeira, Caetité, BA - resultados preliminares. In: SBG, Congr. Bras. Geol., 33, Rio de Janeiro, Anais, 3: 1503-1517.
Amaral G. \& Pascholati E.M. 1998. Transformação dos dados aerogeofísicos do Projeto Rio das Velhas para uso em integração de dados. In: SBG, Congr. Bras. Geol., 40, Belo Horizonte, Boletim de Resumos, p. 396.

Bizzi L., Schobbenhaus C., Gonçalves J.H., Baars F.J., Delgado I.M.O., 


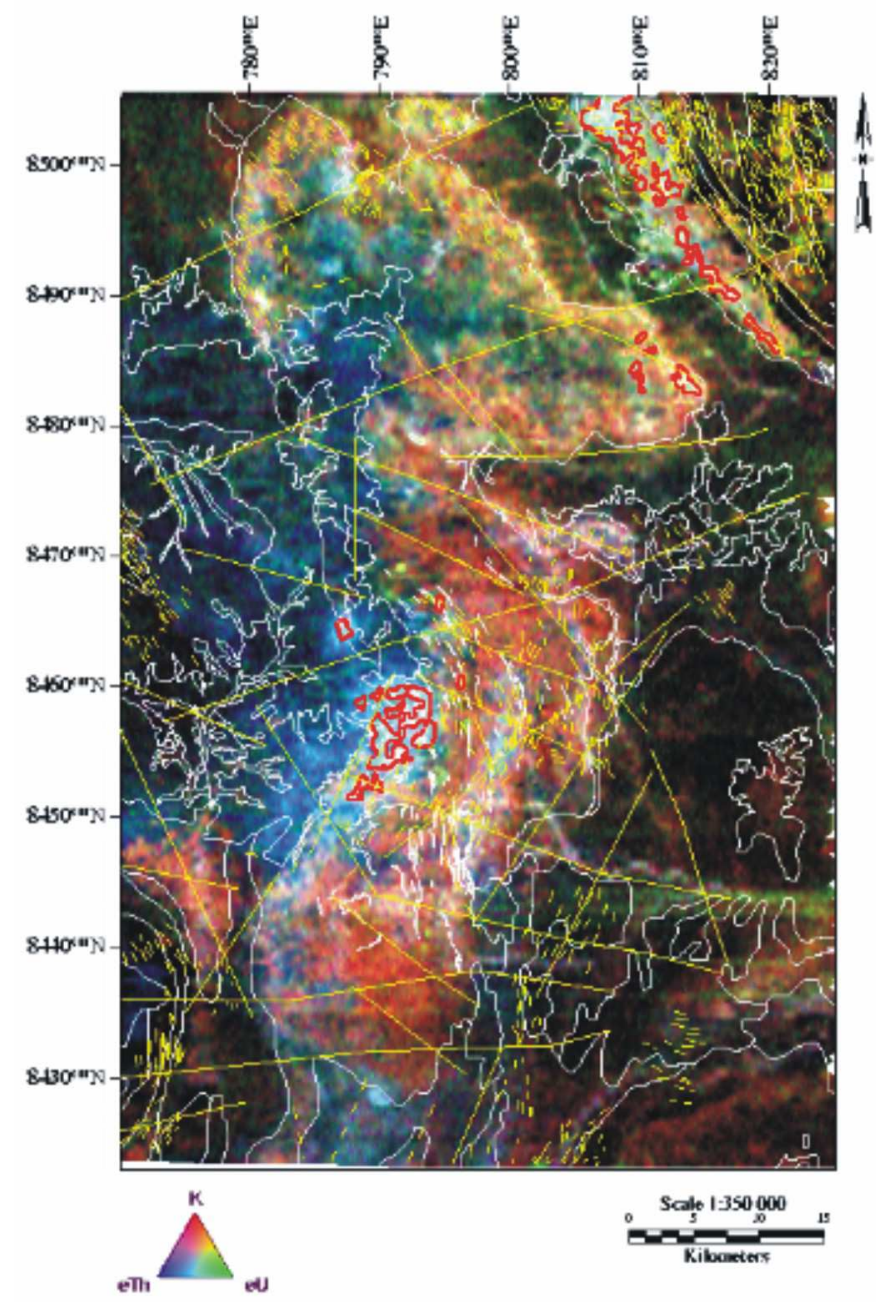

Figura 7 - Integração da imagem ternária $R G B$ - KeUeTh com as unidades geológicas (linhas brancas) e os lineamentos estruturais extraídos da magnetometria e do sensor Landsat-5TM (linhas amarelas) e áreas anômalas conhecidas e propostas (linhas vermelhas).

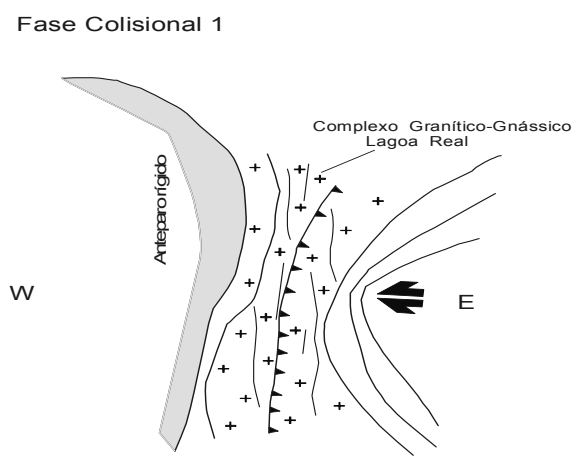

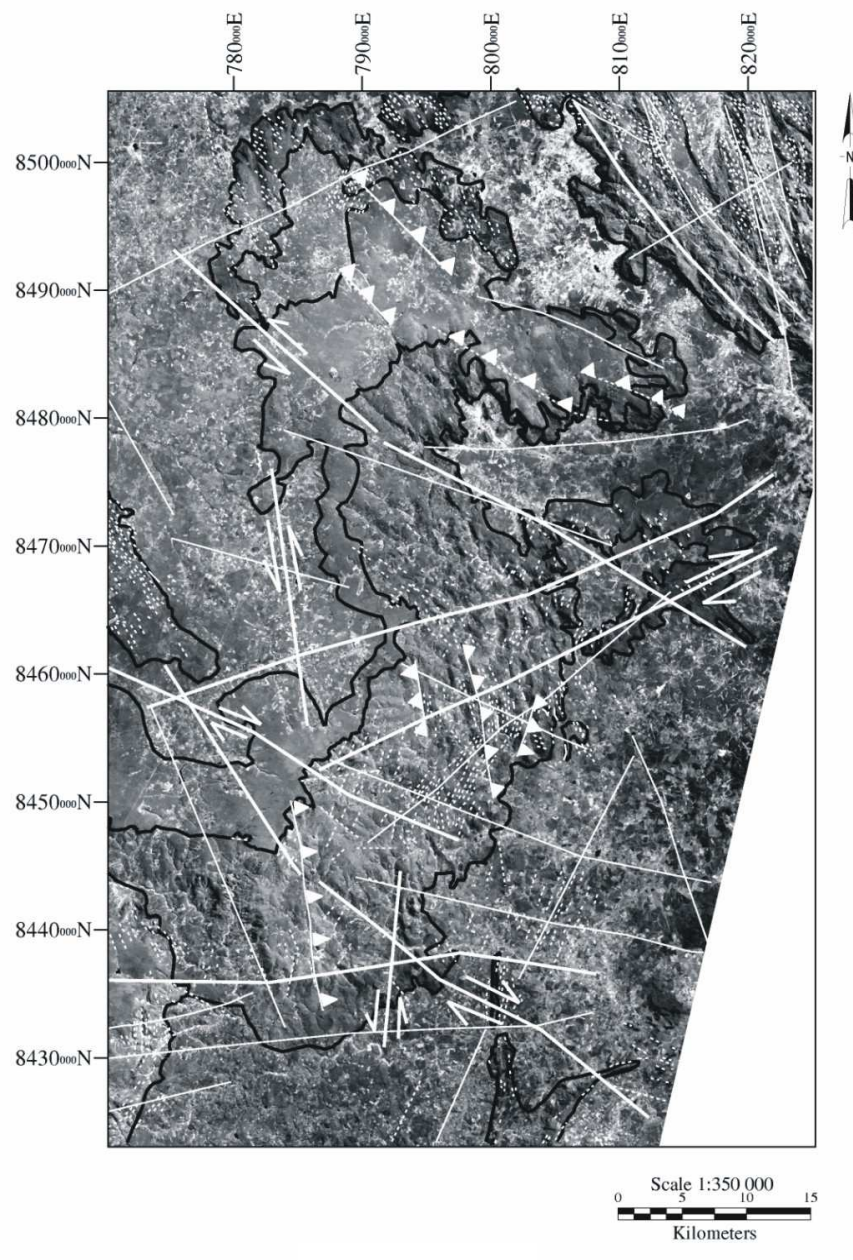

Figura 8 - Imagem da banda 4 do Landsat-5TM com as principais zonas de cisalhamento da região do Distrito Uranifero de Lagoa Real. Lineamentos (linhas brancas contínuas), foliação (linhas brancas tracejadas) e contacto morfológico (linhas pretas).

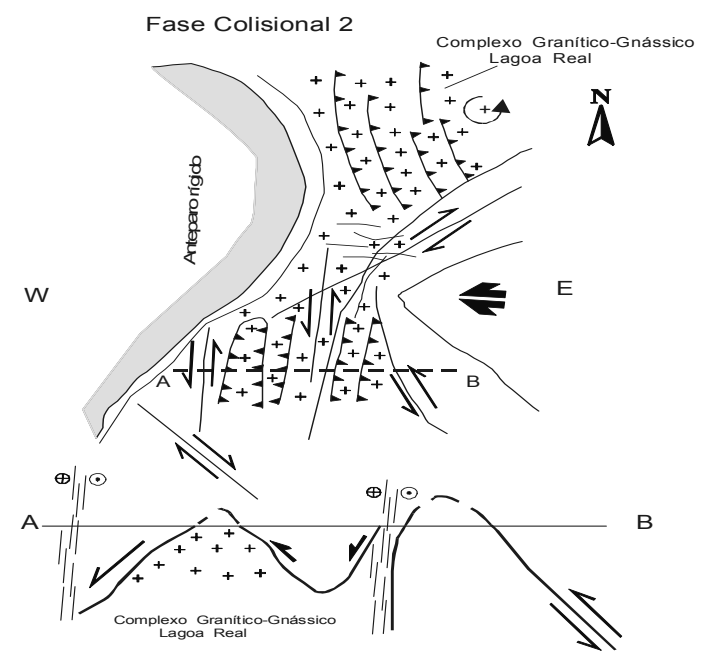

Figura 9 - Modelo esquemático das duas fases da evolução do sistema tectônico do Distrito Uranífero Lagoa Real. 
Abram, M.B., Leão Neto, R., Matos, G.M.M., Santos, J.O.S. 2001. Mapa geológico do Brasil. Geologia, Tectônica e Recursos Minerais do Brasil: Sistema de Informações Geográficas - SIG. Mapas - Escala 1:2.500.000. CPRM, Brasília, Registro Digital. 4 CD-ROM.

Briggs I.C.1974. Machine contouring using minimum curvature. Geophysics, 39:38-48.

Brito W., Raposo C., Matos E.C. 1984. Os albititos uraníferos de Lagoa Real. In: SBG, Congr. Bras. Geol., 33, Rio de Janeiro, Anais, 3: 14751488.

Caby R. \& Arthaud M. 1987. Petrostructural evolution of the Lagoa Real subalkaline metaplutonic complex (Bahia, Brazil). Rev. Bras.Geoc., 17:636.

Clark D.A. 1997. Magnetic petrophysics and magnetic petrology: aids to geological interpretation of magnetic surveys. AGSO J. Austr. Geol. Geophysics, 17:83-103.

Cordani U.G. \& Brito Neves 1982. The geologic evolution of South America during the Archaean and Early Proterozoic. Rev. Bras. Geoc., 12:78-88.

Cordani U.G., Iyer S.S., Taylor K., Kawashita K., Sato K., McReath I. 1992. Pb-Pb, Rb-Sr, and K-Ar systematics of the Lagoa Real uranium province (south-central Bahia, Brazil) and the Espinhaço Cycle (ca. 1.5-1.0 Ga). J. South Am. Earth Sciences, 5:33-46.

Costa P.H.O, Andrade A.R.F, Lopes G.A., Souza S.L. 1985. Projeto Lagoa Real. Mapeamento Geológico, 1:25.000. Nuclebrás/CBPM, Salvador, Bahia, $98 \mathrm{p}$.

Costa S.S, Pascholati E.M, Silva C.L. 2002. Análise estrutural do Cinturão Guiana Central, Roraima, através de dados aeromagnéticos. In: SBG, Congr. Bras. Geol., 51, João Pessoa, Boletim de Resumos, p. 156.

CPRM. 1995. Catálogo geral de produtos e serviços. Geologia. Levantamentos Aerogeofisicos. Base de dados Aerogeofísicos, Rio de Janeiro, Geologia e Recursos Hídricos, 367 p.

Cruz S.C.P. \& Alkmin F.F. 2002. O arcabouço estrutural dos gnaisses Lagoa Real na porção sul do corredor do Paramirim (BA): evidências do envolvimento do embasamento do Cráton do São Francisco durante a interação brasiliana entre o corredor Paramirim e a faixa Araçuaíoeste Congo. In: SBG, Congr. Bras. Geol., 51, João Pessoa, Boletim de Resumos, p. 301.

Dickson B.L. \& Scott K.M. 1997. Interpretation of aerial gamma ray surveys-adding the geochemical factors. AGSOJ. Austr. Geol. Geophysics, 17:187-200.

Drury S.A. 1987. Image interpretation in geology. Allen \& Unwin, London, $243 \mathrm{p}$.

Duval J.S. 1985. Composite color images of aerial gamma-ray data. Geophys. Journal, 48:722-735.

Fuzikawa K. 1982. Alguns carbonatos do distrito uranífero de Lagoa Real, Bahia: estudo de inclusões fluidas e isótopos estáveis. In: SBG, Congr. Bras. Geol., 32, Salvador, Anais, 5:2072-2085.

Fyfe W.S. 1979. The geochemical cycle of uranium. Philos. Trans. Royal Soc. London, 291A: 432-452.

Gnojek.I, Prichystal, A 1985. A new aim mineralization detected by airborne gamma-ray spectrometry in northern Moravia (Czechoslovakia). Geoexploration, 23:491-502.

Grasty R.L. 1975. Uranium measurements by airborne gamma-ray spectrometry. Geophysics, 40:503-519.

Gunn P.J. 1997a. Application of aeromagnetic surveys to sedimentary basin studies. AGSO J. Austr. Geol. Geophys., 17:133-144.

Gunn P.J. 1997b. Regional magnetic and gravity responses of extensional sedimentary basins. AGSO J. Austr. Geol. Geophys., 17:115-131.

Gunn P.J. \& Dentith M.C. 1997. Magnetic responses associated with mineral deposits. AGSO J. Austr. Geol. Geophys., 17:145-158.
Inda H.V.A. \& Barbosa J.S.F. 1996. Texto explicativo para o mapa geológico do Estado da Bahia (1:1.000.000). In: J.S.L. Barbosa \& J.M.S. Dominguez. Geologia da Bahia (texto explicativo). Salvador, Secretaria da Industria, Comércio e Mineração, Superintendência de Geologia e Recursos Minerais, 400 p.

Lobato L.M., Forman J.M.A., Fuzikawa K. 1983a. Uranium in overthrust archaean basement, Bahia, Brazil. Can. Mineral., 21: 647-654.

Lobato L.M., Forman J.M.A., Fyfe W., Kerrich R., Barnett R.L. 1983b. Uranium enrichment in archaean crustal basement associated with overthrusting. Nature, 303:235-237.

Lobato L.M. \& Fyfe W. 1990. Metamorphism, metasomatism and mineralization at Lagoa Real, Bahia, Brazil. Econ. Geol., 85:968-989.

Maruéjol P., Cuney M., Fuzikawa K., Netto A.M., Poty B. 1987. The Lagoa Real subalkaline granitic complex (South Bahia, Brazil): a source for uranium mineralizations associated with $\mathrm{Na}-\mathrm{Ca}$ metasomatism. Rev.Bras.Geoc., 17:578-594.

Milligan, P.R. , Gunn, P.J. 1997. Enhancement and presentation of airborne geophysical data. AGSO J.Austr.Geol.Geophys., 17:63-76.

Minty B.S.R. 1991. Simple micro-levelling for aeromagnetic data. Explor. Geophys., 22:591-592.

Nettleton L.L \& Cannon J.R. 1962. Investigation of upward continuation system. Geophysics, 27: 796-806.

Oliveira A.G., Fuzikawa K., Moura L.A.M., Raposo C. 1985. Província uranífera de Lagoa Real - Bahia. In: C. Schobbenhaus. (ed.). Principais Depósitos Minerais do Brasil, 1, DNPM-MME: 105-120.

Osako L.S. 1999. Estudo do potencial mineral do depósito uranifero de Lagoa Real, BA, com base em dados geológicos, aerogeofisicos e sensoriamento remoto. Dissertação de Mestrado, Instituto de Geociências, Universidade Estadual de Campinas, 93 p.

Osako L.S., Amaral G., Pascholati E.M. 1997. Imagens geofísicas do K, U e Th da Província Uranífera de Lagoa Real (BA), com base no levantamento aerogamaespectrométrico do Projeto São Timóteo. In: SBGf, Intern. Congr. Geophys., 5, São Paulo, Anais, 1:574-576.

Osako L.S. \& Amaral G. 2000. Integrated analysis of airborne radiometric and magnetic data for the Lagoa Real District, Bahia, Brazil. In: SBG, Intern. Geol. Congr., Rio de Janeiro, Boletim de Resumos, CD-ROM.

Raposo C., Matos E.C., Brito W. 1984. Zoneamento cálcio-sódico nas rochas da província uranífera de Lagoa Real. In: SBG, Congr. Bras. Geol., 33, Rio de Janeiro, Anais, 3:1489-1402.

Ribeiro C.I., Carvalho Filho C.A., Hashizume B.K. 1984. As jazidas de Urânio de Lagoa Real. In: SBG, Congr. Bras. Geol., 33, Rio de Janeiro, Anais, 3:1463-1474.

Solovov A.P. 1987. Geochemical Prospecting. Mir Publishers, Moscow, $287 \mathrm{p}$.

Turpin L., Maruéjol P., Cuney M. 1988. U-Pb, Rb-Sr and Sm-Nd chronology of granitic basement, hydrothermal albitites and uranium mineralization (Lagoa Real, South-Bahia, Brazil). Contrib. Mineral. Petrology, 98:139-147.

Villaça J.N. \& Hashizume B.K. 1982. Distrito uranífero de Lagoa Realreservas e potencial. In: SBG, Congr. Bras. Geol., 32, Salvador, Anais, 5:2048-2061.

Wilford J.R., Bierwirth P.N., Craig M. A. 1997. Application of airborne gamma-ray spectrometry in soil/ regolith mapping and applied geomorphology. AGSO J. Austr. Geol. Geophys., 17:201-216.

Manuscrito SR-12

Recebido em 21 de dezembro de 2002

Revisão dos autores em 20 de março de 2003

Revisão aceita em 21 de abril de 2003 